\title{
Evaluation of laparoscopic cholecystectomy in cirrhotic patients
}

\author{
Hamed H Abo Steit, MD, MRCS; Ahmed S Morad, MD; Mahmoud Saad, MD \\ Department of General Surgery, Ain Shams University, \\ Cairo, Egypt.
}

\begin{abstract}
Background: Traditionally cholecystectomy in cirrhotic patients is restricted to severe biliary disease, because of high morbidity and mortality following the procedure. Laparoscopic cholecystectomy $(L C)$ was originally contraindicated in cirrhotic patients because of associated portal hypertension and coagulopathy.

Patients and methods: Fifty cirrhotic patients underwent LC in Ain Shams University Hospital from January 2007 till December 2008.

Results: There were no mortalities in our group. Mean age was 45.6 years and mean operative time was $74.5 \mathrm{~min}$. Conversion to open cholecystectomy occured in 12 patients (24\%). Postoperative complications occurred in 9 patients (18\%). Mean hospital stay was 3.4 days in Child A and 6.8 days in Child $B$.

Conclusion: Laparoscopic cholecystectomy can be performed safely in cirrhotic patients with well compensated liver functions.
\end{abstract}

\section{Introduction:}

The prevalence of gall stones in patients with liver cirrhosis is as twice in comparison to general population. ${ }^{1}$ Although mostly asymptomatic and having lower incidence of complications, these complications can be life threatening in cirrhotic patients. ${ }^{2}$ The risk of biliary surgery in patients with liver cirrhosis can be reduced by preoperative preparation but the problem of unknown cirrhotics remains. ${ }^{3}$ Until recently, liver cirrhosis has been considered to be a contraindication to laparoscopic cholecystectomy. Now there is increasing evidence that patients with liver cirrhosis may safely undergo laparoscopic cholecystectomy with results superior to open cholecystectomy. ${ }^{4}$ Selection of patients with liver cirrhosis according to the liver reserve is the key issue for safe laparoscopic cholecystectomy. ${ }^{5}$ Our study is to evaluate the safety and efficacy of laparoscopic cholecystectomy in patients with liver cirrhosis.

\section{Patient and methods:}

Over a period of 24 months (from January 2007 till December 2008) at Ain Shams University Hospital, 50 consecutive patients with cholelithiasis associated with liver cirrhosis underwent laparoscopic cholecystectomy. Cirrhosis was either diagnosed preoperatively or discovered retrospectively intraopertively. Preoperative diagnosis of cirrhosis was determined according to clinical history and laboratory data. All patients were subjected to preoperative investigations in the form of complete blood picture, liver function tests, hepatitis markers, renal function tests, prothrombin time and abdominal ultrasonography to assess liver parenchyma, gall bladder wall, number and size of stones, biliary radicals and ascitis. Patients proved to have liver cirrhosis preoperatively were classified according to Child classification to either Child A or B. All patients were given antibiotic prophylaxis before induction of anesthesia. Reusable instruments were used. Patients were positioned in supine position. The operative procedure was standardized as laparoscopic cholecystectomy. All patients had the open Hasson technique for insertion of umbilical port with inspection of the liver and gall bladder then all other ports were placed by prior transillumination of the abdominal wall through the scope of the umbilical port Figure(1). 


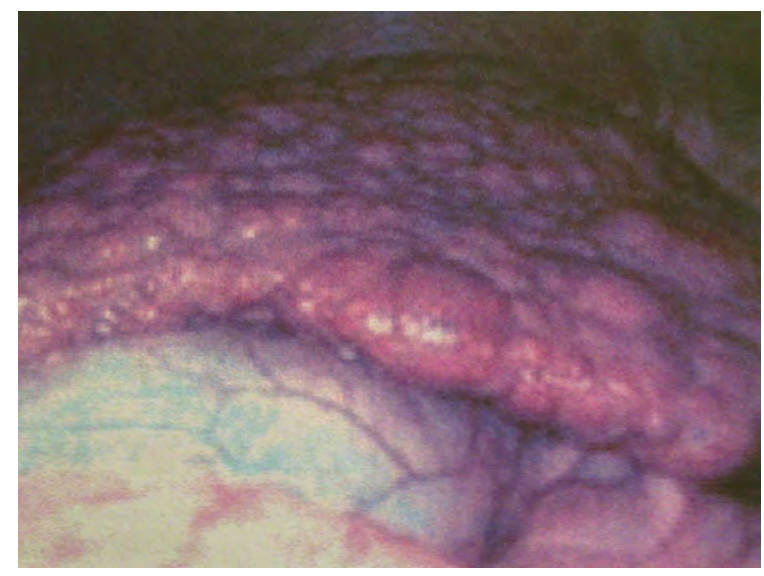

Figure (1)

The subxiphoid $10 \mathrm{~mm}$ port was placed more to the right of the midline to completely avoid the falciform ligament and its accompanying umbilical vein. Traction of the gall bladder was kept to minimum. Dissection of cystic pedicle was carried out with a variety of instruments e.g. Maryland's grasper or electrosurgical hook knife Figure(2).

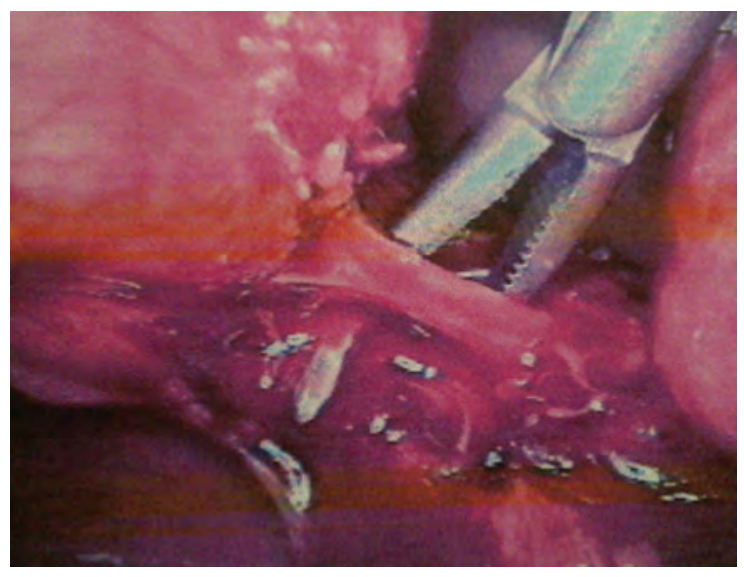

Figure (2)

The cystic duct and artery were divided between two proximal and single distal clips. The gall bladder was dissected from the gall bladder bed in the liver by electro-cautery and was removed from the $10 \mathrm{~mm}$ epigasteric port. Suction irrigation was not done routinely. Closed suction drain was used. Ports were removed. Fascia of the $10 \mathrm{~mm}$ ports was sutured using absorbable sutures, skin is then closed by non absorbable sutures.

\section{Results:}

Our study included 50 patients with cholelithiasis and liver cirrhosis underwent laparoscopic cholecystectomy from Jan. 2007 till Dec. 2008. The study included 14 males and 36 females, there mean age was 45.6 years (range 22-65 years). The indication for the operation was recurrent attacks of biliary colic in 46 patients and acute cholecystitis in 4 patients. 16 patients $(32 \%)$ were diagnosed preoperatively by ultrasound to have liver cirrhosis, whereas 34 patients $(68 \%)$ were discovered intraopertive. Ultrasonography was done pre-operative for those patients and revealed normal liver in 10 patients, fatty liver in 20 patients and hepatomegaly in 4 patients. $16(32 \%)$ patients had elevated liver enzymes, 12 of them were having markedly elevated liver enzymes (2-3 times normal). Serum albumin was low in 10 patients (20\%) (2.7$3.2 \mathrm{gm} / \mathrm{dl})$. Serum bilirubin was elevated in 6 patients (12\%) (1.8-3.1 mg/dl), 2 patients of them were having bilirubin level above $2.5 \mathrm{mg} / \mathrm{dl}$ for whom ERCP was done to remove CBD stones. Prothrombin time was prolonged 5 seconds above normal control in 2 patients (4\%), 2 seconds above normal in 2 patients 
(4\%), 1 second above normal in 8 patients $(16 \%)$ and normal in 38 patients (76\%). 12 (24\%) patients were Hepatitis C virus +ve and 4 patients $(8 \%)$ were Hepatitis B virus +ve. Upper GIT endoscopy was done preoperatively for 4 patients, 2 patients (4\%) were diagnosed to have non bleeding esophageal varices and 2 patients (4\%) had lower end esophagitis and gastritis. Postoperatively 2 patients (4\%) developed haematemesis; upper GIT endoscope was done and revealed bleeding varices. According to Child classification; 40 patients (80\%) were Child A, 27 of them (54\%) gained score 5 and 13 (26\%) gained score 6.10 patients $(20 \%)$ were Child B; 6 of them (12\%) gained score 7,2 patients $(12 \%)$ gained score 8,2 patients $(12 \%)$ gained score 9 . No patients with Child $\mathrm{C}$ were included in the study.

Table (1): Postoperative morbidity and length of stay stratified according with Child Pugh classification.

\begin{tabular}{|l|c|cc|}
\hline \multicolumn{4}{|c|}{ Child classification } \\
\hline No. of patients & Child A & Child B \\
\hline & 40 & 10 \\
\hline \multicolumn{3}{|c|}{ Post operative morbidity } \\
\hline Haematemesis & 0 & \multicolumn{2}{|c|}{2} \\
\hline Wound infection & 1 & & 2 \\
\hline Ascitis & 1 & & 0 \\
\hline Biliary leakage & 1 & & 6.8 \\
\hline & & Length of hospital stay & 8 \\
\hline Mean days & 3.4 & & \\
\hline Conversion & 4 & & \\
\hline
\end{tabular}

There was statistically significant difference in the outcome comparing Child A with Child B patients.

The hospital stay was prolonged in Child B patients, so it can be seen that Child's B cirrhosis have significantly greater risk of bleeding, rate of conversion to open cholecystectomy and prolonged hospital stay. None of the cirrhotic patients developed postoperative liver cell failure or hepatic coma.

\section{Operative details:}

38 procedures $(76 \%)$ were completed laparoscopic within a mean time $74.5 \mathrm{~min}$ (Range 20-120 min), whereas 12 procedures were converted to open cholecystectomy after 10 to $30 \mathrm{~min}$ from the start of the laparoscopic trial. Causes of conversion were as follows:
In 5 patients; conversion was due to uncontrolled bleeding either from port sites ( 3 patients) or from the adhesions at Callot' triangle (2 patients). Only 1 patient required intraoperative blood transfusion and fresh frozen plasma. In 4 patients there were extensive adhesions at Callot triangle obscuring normal anatomy. In 2 patients due to severely contracted intrahepatic gall bladder with thick wall that couldn't be grasped by laparoscopic instruments. In one patient there was bleeding from liver attachments at dissection that couldn't be controlled laparoscopically. 


\section{Discussion:}

Cholelithiasis is a common disease among patients with cirrhosis. ${ }^{6}$ Open cholecystectomy in cirrhotic patients is associated with high morbidity and mortality rate up to 17 to $27 \% .7,8$ In early surgical experiences with LC, cirrhosis was thought to be absolute or relative contraindication because of potential risks of bleeding and liver failure. ${ }^{8,9}$ Only patients with Child's class A and B cirrhosis were operated on.

\section{In our study:}

Ascitis developed in 3 patients. All resolved with medical management. We believe that ascitis should be looked for in the postoperative period. We currently advise our patients to restrict dietary salt and water and to record daily weight. The patients are seen weekly for one month and if ascitis is suspected spironolactone is prescribed. 3 patients developed wound infection in the $3 \mathrm{rd}$ postoperative day in whom the operation was converted to open cholecystectomy. The condition was improved by daily dressing and medical treatment.

2 patients (4\%) experienced postoperative haematemesis and underwent upper GIT endoscopy which revealed esophageal varices. Injection sclerotherapy was done for both patients Table(1). In one patient where the procedure was completed laparoscopic, biliary leak was noticed on the 3 rd postoperative day ( $500 \mathrm{cc}$ in the haemovac in 24 hours). The patient underwent ERCP, which revealed slipped clip. A stent was inserted during ERCP, and the patient was discharged on the 7th postoperative day in good general condition.

Several studies have examined the efficacy and safety of LC in cirrhotics and results have been encouraging Table(2).

Table (2): LC in patients with Child's A and B cirrhosis.

\begin{tabular}{|c|c|c|c|c|c|c|c|}
\hline \multirow{2}{*}{ Author } & \multirow{2}{*}{ Year } & \multirow{2}{*}{$\begin{array}{c}\text { No. of } \\
\text { patients }\end{array}$} & \multicolumn{2}{|c|}{ Child-Pugh } & \multirow{2}{*}{$\begin{array}{c}\text { Morbidity, } \\
\text { n }(\%)\end{array}$} & \multirow{2}{*}{$\begin{array}{c}\text { Hospital } \\
\text { stay }\end{array}$} & \multirow{2}{*}{$\begin{array}{l}\text { Operative } \\
\text { time }\end{array}$} \\
\hline & & & $\bar{A}$ & B & & & \\
\hline Urban et al ${ }^{4}$ & 2001 & 19 & 19 & 0 & 0 & 3.5 & 64 \\
\hline Clark et al ${ }^{11}$ & 2001 & 23 & 14 & 9 & $13(52)$ & 4 & 107 \\
\hline Tuech et $\mathrm{al}^{9}$ & 2002 & 26 & 22 & 4 & $7(27)$ & 5 & 126 \\
\hline Yeh et al ${ }^{12}$ & 2002 & 226 & 193 & 33 & $15(6.6)$ & 4.5 & -- \\
\hline Cucinotta et al ${ }^{7}$ & 2003 & 22 & 12 & 10 & $8(36)$ & 5 & 115 \\
\hline Wu Ji et al ${ }^{10}$ & 2004 & 34 & 19 & 15 & $7(13.2)$ & - & -- \\
\hline Our study & 2008 & 50 & 40 & 10 & $9(18)$ & 5 & 74.5 \\
\hline
\end{tabular}

These data seem to be correlated with several causes. Magnification of the surgical field in laparoscopy permits meticulous hemostasis. Furthermore when performing LC in cirrhotic patients some modifications should be made to avoid the risk of heavy bleeding. First, avoid bleeding from periumbilical wall varices. Second, transillumination of the abdominal wall by the laparoscope helps to identify major collaterals in the abdominal wall. Third, placement of the subxiphoid port should be more to the right of the midline to avoid injury of the faciform ligament. Fourth, excessive traction must be avoided to prevent avulsion of the gall bladder from the liver bed and bleeding.

Based on our results as well as those of others, LC is safe procedure that should be the treatment of choice for symptomatic cholelithiasis or cholecystitis in well-selected Child-Pugh A and B cirrhotic patients. 


\section{References:}

1- Tuech JJ, Pessaux P, Regenet N, Rouge C, Arnaud JP: Laproscopic cholecystectomy in cirrhotic patients. Surg Laprosc End 2002; 4: 227-231.

2- Yerdel M A, Koksoy C, Aras N, et al: Laparoscopic versus pen cholecystectomy in cirrhotic patients: A prospective study. Surg Laparosc Endosc 1997; 7 (6): 483486.

3- Hamid S, et al: Outcome of biliary tract surgery in unknown cirrhotics: A case control study. Ann Royal Coll Surg Eng 1993; 75: 434-436.

4- Urban L, Eason GA, ReMine S, et al: Laparoscopic cholecystectomy in patient with early cirrhosis. Curr Surg 2001; 58: 312.

5- Sleeman D, et al: Laparoscopic cholecystectomy in cirrhotic patients. $J \mathrm{Am}$ Coll Surg 1998; 187 (4): 400-403.

6- Bouchier IAD: Postmortem study of the frequency of gallstones in patients with cirrhosis of the liver. Gut 1969; 10: 705.
7- Cucinotta E, Lazzara S, Melita G: Laparoscopic cholecystectomy in cirrhotic patients. Surg Endosc 1958; 17: 2003.

8- Gadacz TR, Talamini MA: Traditional versus laparoscopic cholecystectomy. Am J Surg 1991; 161: 336.

9- Tuech JJ, Pessaux P, Regenet N, et al: Laparoscopic cholecystectomy in cirrhotic patients. Surg Laparosc Endosc Percutan Tech 2002; 12: 227.

10-Wu Ji, Li LT, Chen XR, et al: Application of laparoscopic cholecystectomy in patients with cirrhotic portal hypertension. Hepatobili Pancreat Dis Int 2004; 3: 270.

11-Clark JR, Wills VL, Hunt DR: Cirrhosis and laparoscopic cholecystectomy. Surg Laparosc Endosc Percutan Tech 2001; 11: 65.

12-Yeh CN, Chen MF, Jan YY: Laparoscopic cholecystectomy in 226 cirrhotic patients. Surg Endosc 2002; 16: 1583. 